\title{
A Prospective Study of Clinical Factors (BMI, DM) Influencing Healing of Abdominal Incisions Correlated with Tissue Expression of MMP2, MMPg and TIMP
}

\author{
Venkat Vaijnath Cholleti ${ }^{\odot}$, Mohd. llyas ${ }^{\circledR}$ \\ Assistant Professor, Department of Surgery, Surabhi Institute of Medical Sciences, Siddipet, Mundrai,, Telangana, India.
}

\section{Abstract}

Background: There is a dynamic and reciprocal interaction among ECM and involving cells, cytokines, growth factors and proteases (MMP/TIMP). The controlled degradation of ECM by extracellular proteases particularly MMP/TIMP and serene proteases forms the basis of wound healing. To study clinical factors (BMI, DM) influencing healing of acute abdominal surgical wounds as graded by tissue expression of MMP 2, MMP 9 and TIMP. Subjects and Methods: The present study was conducted in 46 patients in the Department of General Surgery, Kamineni Hospitals, L.B. Nagar, Hyderabad. Results: Type II DM was found in $63 \%$ of patients and found to be having significantly affecting wound healing $(\mathrm{p}=0.0017)$. Wound healing was delayed in uncontrolled DM. Diabetics with healed wound had increased expression of MMP-2 and decreased expression of MMP-9 while Diabetics with non-healed had strong expression of MMP-9 and TIMP as compared to MMP-2. Obesity was seen in $47.82 \%$ of patients and significantly affected wound healing $(p=0.0022)$. Obese patients with healed wounds had increased expression of MMP-2 and MMP - 9 with decreased TIMP levels. Conclusion: The present study strongly supported tissue expression of MMP-2, MMP-9 and TIMP 2 balance between 7-14 days as a good predictor of wound healing in abdominal laprotomy wounds.

Keywords: Wound Healing, Diabetes Mellitus, Body Mass Index, Matrix Metalloproteinases

Corresponding Author: Mohd. Ilyas, Assistant Professor, Department of Surgery, Surabhi Institute of Medical Sciences, Siddipet, Mundrai,, Telangana, India.

E-mail: surenderjakkam@gmail.com

Received: 16 February 2020

Revised: 29 March 2020

Accepted: 1 April 2020

Published: 5 July 2020

\section{Introduction}

Wound is not just a defect in tissue, it is an insult initiated dynamic biological process. ${ }^{[1]}$ Wound healing is extremely complex and dynamic process which involves cell to cell signaling and cellular and molecular interactions leading to restoration of tissue integrity and function. ${ }^{[2]}$ Conventionally wound healing was divided into 3 stages: inflammation, proliferation, remodeling. ${ }^{[3]}$ Extensive study has been done chronic diabetic wounds to understand the pathophysiology of wound healing. ${ }^{[4-9]}$ It is a collaborative process involving a continuous and reciprocal interaction of variety of cells and Extracellular matrix (ECM) components. The role of ECM as critical zone of wound healing has been studied in detail in recent past. ${ }^{[1,10-13]}$ There is a dynamic and reciprocal interaction among ECM and involving cells, cytokines, growth factors and proteases (MMP/TIMP). The controlled degradation of ECM by extracellular proteases particularly MMP/TIMP and serene proteases forms the basis of wound healing.

Various studies have been made in understanding wound healing at molecular level after discovery of many molecules Growth factors, cytokines, MMP/TIMP. The balance between proteases and anti-proteases (MMP/TIMP) in normal wound healing has been realized recently and opened new avenues for intervention in order to improve wound outcome.

There are balancing forces: MMP 2 - increases wound healing, MMP 9 - Decreases wound healing, TIMPs - Excessive scarring as per previous studies.

Despite increasing knowledge concerning wound healing, the process of wound healing has baffled many surgeons because of its unpredictability. Wound failure might range from superficial wound dehiscence to complete wound failure. ${ }^{[9]}$ Extensive attempts have been made to find out various factors that impede wound healing.Many factors affect wound healing, like Surgeon factors - experience, type of incision, suture material, Patient factors - age, nutrition status, sepsis, 
immunological component, Systemic disorders - Type II DM, Connective tissue disorders, Chronic use of steroids, Local factors- infection, foreign body, radiation treatment to mention a few. ${ }^{[1,14,15]}$ A number of other factors contribute to disrupted wound healing like growth factors and protease-anti-protease balance (MMP/TIMP).

Within MMP family, MMP 2 and MMP 9 play a mutifactorial role in wound healing. They are involved in ECM degradation, cell signaling, Cell migration, proliferation, tissue remodeling. ${ }^{[4,14,16,17]}$

Elevated blood glucose in patients with diabetes mellitus leads to complications including poor wound healing. ${ }^{[18]} \mathrm{A}$ number of studies have been performed characterizing expression of MMP's in chronic wounds. Previous studies have shown generalized increase in MMP activity in chronic wounds. ${ }^{[7,18-20]}$ It is well known that MMP's are important in tissue remodeling but their role in acute wound is poorly studied. Matrix metalloproteinases can be studied by various techniques- ELISA, Western Blot, Immunohistochemistry, Immunofluoresence, Zymography, Gel electrophoresis. ${ }^{[21]}$ It has been studied in tissue, serum, blood, wound fluids in animals and Human beings.

Hence an attempt is made to study the pattern of tissue expression of MMP 2, MMP 9 and TIMP by immunohistochemistry in acute surgical wounds, its correlation to clinical factors and importance in predicting the wound healing.

\section{Aims and Objectives}

1. To study clinical factors (BMI, DM ) influencing healing of acute abdominal surgical wounds as graded by tissue expression of MMP 2, MMP 9 and TIMP.

2. To correlate clinical factors (DM, BMI to wound failure in abdominal incisions.

3. To correlate histological grading of wound with tissue expression of MMP 2,MMP 9 and TIMP.

\section{Subjects and Methods}

This is a prospective study of 46 patients admitted in the Department of General Surgery, Kamineni Hospitals, Hyderabad done during the period of $1 / 8 / 2009$ to $31 / 8 / 2011$. The aim of this study is to predict the outcome of abdominal wound healing using Clinical - diabetes mellitus, BMI, Histological and Biomolecular markers (MMP2,MMP9 and TIMP).

\section{Inclusion criteria}

- All abdominal surgeries irrespective of age, BMI or diabetic status

- Indication - elective and emergency abdominal surgeries

- Type of surgery - Laparotomy

\section{Exclusion criteria}

- Traumatic wounds

Results

There were males $31(61.39 \%)$ and females $15(32.60 \%)$ in the present study.

\section{Wound Status and Duration of Healing}

Wounds 34 (73.91\%) healed completely on clinical grounds within 2 weeks. Remaining patients 12 (26.08\%) took more than 2 weeks. 2 patients took 5 months.

\section{Body mass index}

Out of 46 patients, 8 patients were of normal weight $(17.39 \%)$ (BMI - 18.5 - 22.9), 16 patients were overweight $(34.78 \%$ ) (BMI - 23 - 27.5), 22 patients were obese(47.82\%) (BMI $27.6-40)$. Overall 22 obese and 24 non obese.

Odds ratio -10.1111

$95 \% \mathrm{CI}-2.3052-44.3488$

Statistic -3067

Significance level $-\mathrm{P}=0.0022$

\section{Type II diabetes mellitus}

There were 29 (63.04\%) patients with Type II DM and 17 non diabetic.

Odds ratio -14.2500

$95 \% \mathrm{CI}-2.7032-75.1181$

Statistic -3133

Significance level $-\mathrm{P}=0.0017$

\section{Southampton Clinical Grading}

On clinical grounds $73.91 \%$ of patients healed completely while remaining $12(26.08 \%)$ of patients did not show signs of complete healing by 2 nd week.

$20.58 \%$ of healed wounds showed grade I Southampton Clinical Scoring. While $73.5 \%$ had Grade 2 and 2.94\% had Grade 3 and 4.

Southampton grading system in healed wounds

Southampton Clinical Grading when applied to non-healed wounds, 33.3\% showed Grade 4 and Grade 5, 25\% of nonhealed wounds showed Grade $3,8.33 \%$ of non-healed wounds showed grade 2 .

Chi-square -32.982

$\mathrm{DF}-4$

Significance level $-\mathrm{P}<0.0001$

Contingency coefficient -0.646

Modified Histological Score 
Wounds were also graded histologically. Modified histological score was adapted by our pathologist who was coinvestigator. The Histology was graded from 1-4 on criteria mentioned in Materials and methods.

$11.76 \%$ of healed wounds showed modified Histological score of $2,38.23 \%$ showed score of $3,50 \%$ showed score of 4 from $0-15$ th POD.

$33.3 \%$ of non-healed wounds showed modified histological score of $1,2 \& 4$ while $0 \%$ showed a score of 3 from $0-15$ th POD.

Chi- square -18.490

$\mathrm{DF}-3$

Significance level $-\mathrm{P}=0.0003$

Contingency coefficient -0.535

\section{MMP 2}

MMP -2 expression was graded from 0 to ++++ , weak $(<2+)$ and strong $(>2+)$ and was assessed by two pathologists.

\section{POD}

On 0 POD, $61.76 \%$ showed weak expression of MMP 2, 38.23 $\%$ showed strong expression in healed wounds.

On 0 POD, $83.33 \%$ showed weak expression, $16.66 \%$ showed strong expression in nonhealed wounds.

The pattern of expression of MMP 2 was weak in both healed (21) as well as non-healed (10) and strong in both healed (13) as well as non-healed (2) wounds.

Odds ratio -0.1238

$95 \%$ CI -0.02335 to 0.656

Statistic -2454

Significance level $-\mathrm{P}=0.0141$

\section{$7^{\text {th }}$ POD}

On $7^{\text {th }}$ POD, $23.52 \%$ showed weak expression of MMP 2, $79.41 \%$ showed strong expression in healed wounds.

On $7^{\text {th }}$ POD, $100 \%$ showed weak expression in nonhealed wounds.

The pattern of expression of MMP 2 was strong in healed (27) wounds and weak in non-healed (12) wounds on $7^{\text {th }}$ POD.

Odds ratio -0.1294

$95 \%$ CI -0.006913 to 2.4224

Statistic -1368

Significance level $-\mathrm{P}=0.1713$

\section{$1^{\text {th }}$ POD}

On $15^{\text {th }}$ POD, $100 \%$ showed weak expression in nonhealed wounds.

\section{MMP 9}

On 0 POD, 91.17\% showed weak expression of MMP 9, 11.76 $\%$ showed strong expression in healed wounds.

On 0 POD, $58.33 \%$ showed weak expression of MMP 9, $41.66 \%$ showed strong expression in nonhealed wounds

The pattern of MMP 9 expression was significantly weak (30) and strong (4)in healed wounds on 0 POD and non-healed wounds showed both weak (7) and strong(5) expression.

Odds ratio -10.5000

$95 \% \mathrm{CI}-2.2264$ to 49.5195

Statistic -2971

Significance level $-\mathrm{P}=0.00030$

$7^{\text {th }}$ POD

On $7^{\text {th }}$ POD, $97.05 \%$ showed weak expression and $2.94 \%$ showed weak expression of MMP 9 in healed wounds.

On $7^{\text {th }}$ POD, $83.33 \%$ showed weak expression of MMP 9, $16.66 \%$ showed strong expression in nonhealed wounds.

The pattern of MMP 9 expression was significantly weak(33) and strong (1) in healed wounds on $7^{\text {th }} \mathrm{POD}$ and non-healed wounds showed weak(10) and strong (2) tissue expression.

Odds ratio -165.00

$95 \% \mathrm{CI}-13.50$ to 2015.33

Statistic - 3999

Significance level $-\mathrm{P}=0.0001$

\section{5 ${ }^{\text {th }}$ POD}

On $15^{\text {th }}$ POD, $75 \%$ showed weak expression of MMP 9, 25\% showed strong expression in nonhealed wounds.

\section{TIMP 2}

On 0 POD, 76.47\% showed weak expression of TIMP 2, 23.52 $\%$ showed strong expression in healed wounds.

On 0 POD, $83.33 \%$ showed weak expression of TIMP 2, $16.66 \%$ showed strong expression in nonhealed wounds

The pattern of TIMP 2 expression was weak in both healed (26) and non-healed(10) wounds on 0 POD and strong in healed (8) and non-healed (2) wounds. .

Odds ratio -0.06154

$95 \% \mathrm{CI}-0.0111$ to 0.3411

Statistic -3191

Significance level $-\mathrm{P}=0.0014$

$7^{\text {th }}$ POD

On $7^{\text {th }}$ POD, $79.41 \%$ showed weak expression of TIMP 2, $20.58 \%$ showed strong expression in healed wounds. 
On $7^{\text {th }}$ POD, $100 \%$ showed weak expression of TIMP 2, in non-healed wounds.

The pattern of TIMP 2 expression was weak in healed (27) wounds and non-healed (12)wounds showed 100\% expression, and strong in healed (7) wound on $7^{\text {th }}$ POD.

Odds ratio -0.01091

$95 \%$ CI -0.0005768 to 0.2063

Statistic -3012

Significance level $-\mathrm{P}=0.0026$

$15^{t h}$ POD

On $15^{\text {th }}$ POD, $91.66 \%$ showed weak expression of TIMP 2, $8.33 \%$ showed strong expression in nonhealed wounds.

\section{Discussion}

This present study was conducted to find out the effects of parameters on wound healing and this has been correlated with expression of Matrix Metalloproteinases, an essential component of acute wound healing. Extracellular matrix and the role of MMP's has been validated in the recent past. ${ }^{[4,7,14,16-20,22-24]}$ The present study conducted in 46 acute abdominal wounds to evaluate the effect of the following parameters on healing. Expression of MMP-2, MMP-9 and TIMP were also correlated with the same parameters.

\section{The parameters studied were}

- Type II DM

- Body mass index

- Southampton clinical grading

- Histological grading

- Matrix Metalloproteinases - MMP 2, MMP 9 and TIMP

\section{Type II DM}

Lan $\mathrm{C}$ et al found that, the mobility of keratinocytes, the activities were significantly downregulated after hyperglycaemic treatments It was concluded that under hyperglycemic conditions Keratinocytes demonstrate reduced migration and decreased proliferation capacities which can provide explanation for poor wound healing in diabetic patients. ${ }^{[7]}$

Gabriëlle H. van Ramshorst et al studied the risk factors for abdominal wound dehiscence in adults. 363 patients among 429,906 operative procedures had abdominal wound failure. $\mathrm{DM}$ was not found to be an independent risk factor in their study $(\mathrm{p}=0.917){ }^{[5]}$

$29(63.04 \%)$ out of 46 patients had Type II DM in the present study. In the diabetic group, $19(65.5 \%)$ healed and 10 (34.48\%) nonhealed. Out of the 17 non diabetic patients, 15 $(82.23 \%)$ healed and $2(11.76 \%)$ nonhealed. In this study, Type II Diabetes Mellitus was a significant risk factor for wound healing $(\mathrm{p}=0.0017)$ where $35 \%$ of diabetics had nonhealed wounds and only $11.76 \%$ of nondiabetics had nonhealed wounds.

The present study correlated with study done by Lan C et al who found that Diabetes affects wound healing.

\section{DM And MMP 2, MMP 9, TIMP}

Lan $\mathrm{C}$ et al found that gene expressions of MMP-2 and MMP9 were significantly downregulated after hyperglycemic treatments while the mRNA expression of TIMP-1 increased. ${ }^{\text {[7] }}$

The present study showed diabetic patients with healed wounds had decreased expression of MMP $2(<2)$ and increased expression of MMP $9(>2+)$ and with nonhealed wounds had increased expression of MMP 9 i.e. $(>2+)$ while decreased expression of MMP 2 was $<2+$. Increased expression of MMP 2 and decreased MMP 9 with healed wounds was found in nondiabetic patients. TIMP 2 was increased in healed wounds in diabetics.

There is no other comparable study available in literature to compare with this study.

L lo,SV Mc lennan studied post wound debridement fluid samples of neuropathic foot ulcers in Type 2 DM patients they found a positive correlation $(\mathrm{r}=0.57, \mathrm{p}=0.002)$.

In the present study, Type $2 \mathrm{DM}$ patients tend to have poorer wound healing ( 3 times) $(\mathrm{p}=0.0017)$.

\section{Clinical Scoring System}

Wilson AP et al used the ASEPSIS score for postoperative wound surveillance in 1029 surgical wounds. An ASEPSIS score over 20 points was more sensitive than and as specific as the presence of pus as an indicator of changes in management resulting from infection. Matching 52 infected patients with uninfected controls, any wound score over 10 points was associated with a significant delay in wound healing $(\mathrm{P}<$ $0.0005)^{[25]}$

Z H Krukowski et al assessed 5804 surgical wounds using different scoring systems.(Purulent discharge alone, Centers for Disease Control (CDC) definition of wound infection, on the nosocomial infection national surveillance scheme (NINSS) version of the CDC definition, and on the ASEPSIS scoring method). It was found more than twice as many wounds were classified as infected by only one definition $(n=778)$ as were classified as infected by both $(n=366)$. These Surveillance systems were used to monitor rates of wound infection and form an important component to prevent and control wound infection. ${ }^{[26]}$

Frykberg et al conducted a study for evaluation of clinical wound score to identify lower extremity wounds for comprehensive wound management that uses five criteria: appearance, depth, size, infection and perfusion in 83 lower extremity wounds. Sensitivity, 93, 95, 91; Specificity, 36, 53, 0; Positive 
Pred. Value, 80, 83, 75; Negative Pred. Value, 67, 80, 0; Overall accuracy, 78, 87, 70. They concluded that a simple wound score performed on initial examination of lower extremity problem wounds would be useful in selecting wounds appropriate for comprehensive management that results in wound healing. [27]

The present study used Southampton clinical scoring system, $73.91 \%$ of patients healed completely while remaining 26.08 $\%$ of patients did not show signs of complete healing by 2 nd week. The healed wounds had Southampton Clinical grading less than II while non-healed wounds had Southampton Clinical grading more between III and V. Patients with wound failure showed increased clinical grading. A significant correlation between Sothampton clinical grading system and duration of healing ( $p<0.0001$ ) was found. Longer the Duration of healing for acute wounds higher was the Clinical grading indicating wound failure. Simple clinical grading of wound on each postoperative day can predict the time required for healing and thus wound failure.

The results are comparable to previous studies using ASEPSIS score, Clinical wound score, CDC criteria.

\section{Hitsological Grading}

Jacheman sultana et al studied the histological feature in maxillofacial region. A statistically significant difference was found between study and control group in terms of pattern and relative amount of early and late maturation of collagen tissue $(\mathrm{p}<0.005)$ indicating delayed wound healing among study patients. ${ }^{[28]}$

The present study used modified histological grading; healed wounds were graded 1, 2, 3 and 4. Histological grading correlated significantly with Wound status $(p=0.0003)$. According to this study, Modified Histological grading system can predict the wound status (healed or nonhealed).

\section{MMP 2, MMP 9 \& TIMP}

Gillard JA et al found that Immunohistochemistry scores for matrix metalloproteinase- 9 expression were significantly elevated when compared to controls in wounds from 2 to 20 weeks, respectively. They concluded that Matrix metalloproteinases are present at elevated levels during early wound healing suggests that matrix metalloproteinase-9 may play a significant role. ${ }^{[22]}$

Salo T, Mäkelä M et al studied the expression of MMP2 and MMP -9 during early human wound healing by in situ hybridization. They found MMP-2 was localized in the connective tissue fibroblasts and endothelial cells during all phases of wound healing.MMP 9 was found in granulation tissue 1 week after wounding. They concluded that MMP-9 is involved in later phases of wound healing. Expression of MMP-2 remains stable during wound healing. ${ }^{[23]}$
Ursula Mirastschijski et al compared MMP-9 and MMP2 in wound margin biopsies of standardized acute partialthickness wounds. They found neither MMP-9 $(\mathrm{P}=0.814)$ nor MMP-2 $(\mathrm{P}=0$.742) differed significantly between acute and chronic wound tissues. Acute wound healing was characterized increase in MMP-9 and MMP-2 They concluded that Chronic nonhealing wounds can be distinguished from acute healing wounds by an unfavorable distribution and persistance of MMP-9. ${ }^{[19]}$

Manuel jessica et al studied the expression of MMP 2 and MMP 9 in wound healing in athymic nude mice. Their results showed that MMP-2 protein was high but similarly expressed in all post-injured animals on Day 7 after injury. Late phase (Day 24) of wound repair was characterized by decrease in MMP-2 in all post-injured samples. On the contrary, high $(p<0.001)$ levels MMP-9 were present exclusively in the postinjured tissues from nude mice on Day 24 after wounding. They concluded that matrix metalloproteinase 9 (MMP-9) expression is upregulated during remodeling phase wound healing in athymic nude mice. ${ }^{[24]}$

In the present study, MMP 2 expression was strong in healed wounds throughout, MMP 9 expression was weak in healed wounds, TIMP expression was strong in non-healed wounds $(\mathrm{p}=0.0141$ day $0, \mathrm{p}=0.1713$ day 7$)$.

\section{MMP - 2}

Decreased expression $(<2+)$ of MMP 2 and MMP 9 was found on 0 POD of all patients.

MMP 2 expression was strong $(>2+)$ in healed wounds while weak $(<2+)$ in nonhealed wounds on 7-14 postoperative day.

MMP -2 correlated significantly with Wound status $(\mathrm{p}=0.0141$ for day $0,0.1713$ for day 7$)$. These results were comparable with previous studies of Urusula et al and Gillard et al.

Petra linen jhonsan, Raphael rosh et al studied the role of MMP2 expression and its proteolytic activity in healing wound by quantitative analysis they detected significantly enhanced MMP2 protien expression in macrophages fibroblasts and also in scar tissue on day 7,21 and 90 whereas in normal skin the MMP expression was at basal level which is well correlatedwith our present study $(\mathrm{p}=0.0014)$

\section{MMP - 9}

Decreased expression $(<2+)$ of MMP 2 and MMP 9 was found on 0 POD of all patients.

MMP 9 expression was $\leq 2+$ in healed wounds while it was strongly increased $>2+$ in nonhealed wounds.

MMP-9 correlated significantly with Wound status $(\mathrm{p}<.0001)$ in the present study. These results were comparable with studies of Gillard et al, Ursula et al, Urlich et al, Salo et al and Manuel Jessica et al.

TIMP - 2 
Decreased expression $(<2+)$ of TIMP was found on 0 POD of all patients.

TIMP-2 expression was $\leq 2+$ in healed compared to non healed wounds where it was strongly increased $>2+$.

TIMP - 2 correlated significantly with Wound status $(\mathrm{p}<0.0026)$ in the present study. These results were comparable with studies of Helen cook, Phil stephens, K june davies, Keith G harding.

L lo, SV Mc lennan studied post wound debridement fluid samples of neuropathic foot ulcers in Type 2 DM patients they found a positive correlation $(\mathrm{r}=0.57, \mathrm{p}=0.002)$ between wound healing and connective tissue growth factor they also analysed that total MMP levels tend to decrease as connective tissue growth factor increases $(\mathrm{r}=0.28, \mathrm{p}=0.06)$ however individual MMPs ie, MMP 2 and MMP 9 did not correlate with connective tissue growth factor and wound healing. ${ }^{[4]}$

In the present study, Type $2 \mathrm{DM}$ patients tend to have poorer wound healing $(3$ times) $(p=0.0017)$, MMP 2 expression was strong in healed wounds throughout, MMP 9 expression was weak in healed wounds, TIMP expression was strong in non healed wounds $(\mathrm{p}=0.014$ day $0, \mathrm{p}=0.0026$ day $7, \mathrm{p}=0.014$ day 15).

\section{Conclusion}

The present study strongly supported tissue expression of MMP-2, MMP-9 and TIMP 2 balance between 7-14 days as a good predictor of wound healing in abdominal laprotomy wounds.

\section{References}

1. Robert FD. Wound healing: an overview of acute, fibrotic and delayed healing. Frontiers Biosci. 2004;9:283-286. Available from: https://dx.doi.org/10.2741/1184. doi:10.2741/1184.

2. Han G, Ceilley R. Chronic Wound Healing: A Review of Current Management and Treatments. Adv Ther. 2017;34(3):599610. Available from: http://emedicine.medscape.com/article/ 1298452-overview. doi:10.1007/s12325-017-0478-y.

3. Strecker-McGraw MK, Jones TR, Baer DG. Soft Tissue Wounds and Principles of Healing. Emerg Med Clin North Am. 2007;25:1-22. Available from: https://dx.doi.org/10.1016/j. emc.2006.12.002. doi:10.1016/j.emc.2006.12.002.

4. Mclennan SV, Natfaji A, Chua E, Yue DK, Twigg SM. Topically applied connective tissue growth factor/CCN2 improves diabetic preclinical cutaneous wound healing: potential role for CTGF in human diabetic foot ulcer healing. J Diabetes Res. 2015;2015:236238-236238. doi:10.1155/2015/236238.

5. van Ramshorst GH, Nieuwenhuizen J, Hop WCJ, Arends P, Boom J, Jeekel J, et al. Abdominal Wound Dehiscence in Adults: Development and Validation of a Risk Model. World J Surg. 2010;34:20-27. Available from: https://dx.doi.org/10. 1007/s00268-009-0277-y. doi:10.1007/s00268-009-0277-y.
6. Theodoros E Pavlidis ING. Complete Dehiscence of the Abdominal Wound and Incriminating Factors. Eur J Surg. 2001;167:351-354. Available from: $\quad$ https://dx.doi.org/10.1080/110241501750215221. doi:10.1080/110241501750215221.

7. Lan CCE, Liu IH, Fang AH, Wen $\mathrm{CH}$, Wu CS. Hyperglycaemic conditions decrease cultured keratinocyte mobility: implications for impaired wound healing in patients with diabetes. $\quad \mathrm{Br}$ J Dermatol. 2008;159(5):1103-1118. Available from: https://dx.doi.org/10.1111/j.1365-2133.2008. 08789.x. doi:10.1111/j.1365-2133.2008.08789.x.

8. Col C, Soran A, Col M. Can postoperative abdominal wound dehiscence be predicted. Tokai J Exp Clin Med. 1998;23(3):123-130.

9. Ekmektzoglou KA. A concomitant review of the effects of diabetes mellitus and hypothyroidism in wound healing. World J Gastroenterol. 2006;12(17):2721-2721. Available from: https://dx.doi.org/10.3748/wjg.v12.i17.2721. doi:10.3748/wjg.v12.i17.2721.

10. Robson MC, Mustoe TA, Hunt TK. The future of recombinant growth factors in wound healing. Am J Surg. 1998;176:80S82S. Available from: https://dx.doi.org/10.1016/s00029610(98)00186-x. doi:10.1016/s0002-9610(98)00186-x.

11. Chang HY, Sneddon JB, Alizadeh AA, Sood R, West RB, Montgomery K, et al. Gene Expression Signature of Fibroblast Serum Response Predicts Human Cancer Progression: Similarities between Tumors and Wounds. PLoS Biol. 2004;2:e7e7. Available from: https://dx.doi.org/10.1371/journal.pbio. 0020007. doi:10.1371/journal.pbio.0020007.

12. Garg HG. Scarless Wound Healing. New York Marcel Dekker: Inc. Electronic book; 2000.

13. Schultz GS, Wysocki A. Interactions between extracellular matrix and growth factors in wound healing. Wound Repair Reg. 2009;17:153-162. Available from: https://dx.doi.org/10.1111/j.1524-475x.2009.00466.x. doi:10.1111/j.1524-475x.2009.00466.x.

14. Briquez PS, Hubbell JA, Martino MM. Extracellular MatrixInspired Growth Factor Delivery Systems for Skin Wound Healing. Adv Wound Care (New Rochelle). 2015;4(8):479489. doi:10.1089/wound.2014.0603.

15. Hart J. Inflammation 1: its role in the healing of acute wounds. J Wound Care. 2002;11(6):205-209. Available from: https://dx.doi.org/10.12968/jowc.2002.11.6.26411. doi:10.12968/jowc.2002.11.6.26411.

16. Pilcher BK, Wang MIN, Qin XJ, Parks WC, Senior RM, Welgus HG. Role of Matrix Metalloproteinases and Their Inhibition in Cutaneous Wound Healing and Allergic Contact Hypersensitivity. Ann New York Acad Sci. 1999;878(1):1224. Available from: https://dx.doi.org/10.1111/j.1749-6632. 1999.tb07671.x. doi:10.1111/j.1749-6632.1999.tb07671.x.

17. Parks WC. Matrix metalloproteinases in repair. Wiley; 1999. Available from: https://dx.doi.org/10.1046/j.1524-475x.1999. 00423.x. doi:10.1046/j.1524-475x.1999.00423.x.

18. Lobmann R, Ambrosch A, Schultz G, Waldmann K, Schiweck S, Lehnert H. Expression of matrix-metalloproteinases and their inhibitors in the wounds of diabetic and nondiabetic patients. Diabetologia. 2002;45(7):1011-1016. 
Available from: https://dx.doi.org/10.1007/s00125-002-08688. doi:10.1007/s00125-002-0868-8.

19. Mirastschijski U, Impola U, Jahkola T, Karlsmark T, Ågren MS, Saarialho-Kere U. Ectopic localization of matrix metalloproteinase-9 in chronic cutaneous wounds. Human Pathol. 2002;33:355-364. Available from: https://dx.doi.org/ 10.1053/hupa.2002.32221. doi:10.1053/hupa.2002.32221.

20. Ulrich D, Lichtenegger F, Unglaub F, Smeets R, Pallua N. Effect of Chronic Wound Exudates and MMP-2/9 Inhibitor on Angiogenesis In Vitro. Plastic Reconstructive Surg. 2005;116:539-545. Available from: https://dx.doi.org/10.1097/01.prs.0000173447.81513.7a. doi:10.1097/01.prs.0000173447.81513.7a.

21. Freije JR, Bischoff R. The use of affinity sorbents in targeted proteomics. Drug Discovery Today: Technologies. 2006;3:511. Available from: https://dx.doi.org/10.1016/j.ddtec.2006.03. 002. doi:10.1016/j.ddtec.2006.03.002.

22. Gillard JA, Reed MWR, Buttle D, Cross SS, Brown NJ. Matrix metalloproteinase activity and immunohistochemical profile of matrix metalloproteinase- 2 and -9 and tissue inhibitor of metalloproteinase-1 during human dermal wound healing. Wiley; 2004. Available from: https://dx.doi. org/10.1111/j.1067-1927.2004.012314.x. doi:10.1111/j.10671927.2004.012314.x.

23. Salo T, Mäkelä M, Kylmäniemi M, Autio-Harmainen H, Larjava H; 1994.

24. Manuel JA, Gawronska-Kozak B. Matrix metalloproteinase 9 (MMP-9) is upregulated during scarless wound healing in athymic nude mice. Matrix Biol. 2006;25(8):505-514. Available from: https://dx.doi.org/10.1016/j.matbio.2006.07. 008. doi:10.1016/j.matbio.2006.07.008.

25. Wilson APR, Weavill C, Burridge J, Kelsey MC. The use of the wound scoring method 'ASEPSIS' in postoperative wound surveillance. J Hospital Inf. 1990;16(4):297-309. Available from: https://dx.doi.org/10.1016/0195-6701(90)90002-6. doi:10.1016/0195-6701(90)90002-6.

26. Wilson APR, Gibbons C, Reeves BC, Hodgson B, Liu M, Plummer D, et al. Surgical wound infection as a performance indicator: agreement of common definitions of wound infection in 4773 patients. $\mathrm{Br}$ Med J. 2004;329(7468):720-720. Available from: https://dx.doi.org/10.1136/bmj.38232.646227. de. doi:10.1136/bmj.38232.646227.de.

27. Frykberg RG, Banks J. Challenges in the Treatment of Chronic Wounds. Adv Wound Care (New Rochelle). 2015;4(9):560582. doi:10.1089/wound.2015.0635.

28. Sultana J, Molla MR, Kamal M, Shahidullah M, Begum F, Bashar MA. Histological differences in wound healing in maxillofacial region in patients with or without risk factors. Bangla J Pathol. 2009;24(1):3-8.

Copyright: (C) the author(s), 2020. It is an open-access article distributed under the terms of the Creative Commons Attribution License (CC BY 4.0), which permits authors to retain ownership of the copyright for their content, and allow anyone to download, reuse, reprint, modify, distribute and/or copy the content as long as the original authors and source are cited.

How to cite this article: Cholleti VV, Ilyas M. A Prospective Study of Clinical Factors (BMI, DM) Influencing Healing of Abdominal Incisions Correlated with Tissue Expression of MMP2, MMP9 and TIMP. Acad. J Surg. 2020;3(1):142-148.

DOI: dx.doi.org/10.47008/ajs/2020.3.1.31

Source of Support: Nil, Conflict of Interest: None declared. 